\title{
A Large Volume Multi-Anvil Apparatus for the Earth Sciences Community in Taiwan
}

\author{
Florian B. Hua ${ }^{1}$, Keng-Chih Liang ${ }^{1,3}$, Jennifer Kung ${ }^{1, *}$, Wei-Ling Hsu ${ }^{1}$, and Yanbin Wang ${ }^{2}$ \\ ${ }^{1}$ Department of Earth Sciences, National Cheng Kung University, Tainan, Taiwan \\ ${ }^{2}$ Center for Advanced Radiation Sources, The University of Chicago, Chicago, IL, USA \\ ${ }^{3}$ Institute of Electro-Optical Sciences and Engineer, National Cheng Kung University, Tainan, Taiwan
}

Received 3 January 2012, accepted 7 May 2012

\begin{abstract}
A modified DIA type multi-anvil apparatus was installed in the Department of Earth Sciences, National Cheng Kung University, Taiwan. This modified DIA multi-anvil system is used with a hydraulic press that generates loads of up to 1000 tons and is the first multi-anvil press installed for geoscience research in Taiwan. In this paper, the geometry of the high-pressure apparatus is briefly described and the pressure calibration performed in the press is reported. The thermal behaviors of various pressure mediums, boron-epoxy, zirconia, and mullite, are also compared. Pressure calibrations at room temperature were performed with different cell designs, paying special attention to the so called "D" factor, which is defined as the ratio of diagonal length of the cell assembly cube to the diameter of the cavity hole. For a given cell design, the sample-pressure efficiency for the three materials examined was similar. Calibrations with different cell designs showed that increasing the " $D$ " value results in greater pressure generation efficiency. By comparing the deformation behavior at high temperatures (up to $1200^{\circ} \mathrm{C}$ ), the semi-sintered mullite and zirconia appeared to be better pressure mediums compared to boron-epoxy.
\end{abstract}

Key words: High pressure, High pressure multi-anvil apparatus, Solid earth, Pressure calibration

Citation: Hua, F. B., K. C. Liang, J. Kung, W. L. Hsu, and Y. Wang, 2012: A large volume multi-anvil apparatus for the Earth Sciences community in Taiwan . Terr. Atmos. Ocean. Sci., 23, 647-655, doi: 10.3319/TAO.2012.05.07.01(TT)

\section{INTRODUCTION}

The solid Earth comprises multi-phase, polycrystalline minerals. The physical and chemical properties of these minerals control the dynamics within the Earth, as manifested by the observed seismic discontinuities (generally considered to be due to the structural phase transitions of silicates), and plate tectonics arising from convection of Earth materials within the mantle. Therefore, studies of the properties of Earth materials at high pressures and temperatures are crucial for understanding the observed geophysics and geochemistry.

In order to study the properties of materials in the deep interior of the Earth, two different types of devices are commonly used for high pressure experiments; the diamond anvil cell (DAC) and the large volume press (LVP). Pressure in the DAC is generated by compressing samples between small flat surfaces (namely culets) at the tips of two

\footnotetext{
* Corresponding author

E-mail:jkung@mail.ncku.edu.tw
}

gem-quality diamonds. In order to generate high pressure, the size of the culet is often small $(0.1-1 \mathrm{~mm})$, limiting the sample volume to less than $10^{-3} \mathrm{~mm}^{3}$. Due to its small size, the DAC is probably the most commonly used such piece of equipment in high-pressure research. Compared to the DAC, the size of the sample held within the LVP can be on the order of $1 \mathrm{~mm}^{3}$ or larger, with better control for the experimental conditions, such as smaller thermal gradient within a well-designed sample chamber, hence offering great advantages in many experiments, especially for studying multi-phase materials in petrology and geochemistry. LVPs with different multi-anvil modules have been used to generate pressure in the range of 3 - $125 \mathrm{GPa}$ while simultaneously heating to temperatures up to $\sim 3000 \mathrm{~K}$ (Rubie 1999; Frost et al. 2004; Kunimoto and Irifune 2010). These types of LVPs have been utilized for synthesis of high pressure phases (e.g., coesite: Coes 1953; diamond: Bundy et al. $1955 ; \mathrm{MgSiO}_{3}$-perovskite: Ito and Weidner 1986), phase equilibrium investigation using quenching techniques (e.g., 
olivine-spinel: Ringwood 1958, 1963; Ringwood and Seabrook 1962; coesite-stishovite: Yagi and Akimoto 1976; garnet: Akaogi and Akimoto 1977, 1979; $\mathrm{MgO}-\mathrm{FeO}-\mathrm{SiO}_{2}$ : Ito et al. 1984), and high pressure and high temperature insitu measurements (e.g., X-ray diffraction: Inoue and Asada 1973; elasticity measurements: Chen et al. 1996; viscosity measurements: Dobson et al. 1996; electrical conductivity: $\mathrm{Xu}$ et al. 2000).

We have installed a large volume high pressure apparatus in the Department of Earth Sciences, National Cheng Kung University, Taiwan. This is the first LVP system for the geoscience community in Taiwan. In this report, we briefly introduce the geometry of this type of LVP, present the results of pressure calibrations within the press, and discuss the behaviors of various cell assemblies.

\section{LARGE VOLUME MULTI-ANVIL PRESS}

The installed large volume multi-anvil press system (LVP) is comprised of a hydraulic press, a multi-anvil device, and a pressure-temperature controlling system (Fig. 1). The press system is equipped with a 1000-ton capacity hydraulic system and the frame is built with a double-sided rail system in order to accommodate two sets of multi-anvil modules, which can be interchanged on a run-to-run basis. Currently, the multi-anvil device is a Deformation-DIA type cubic-anvil module, which was modified from the original DIA-type module (Fig. 2). The geometry of the DIA is described in detail elsewhere (e.g., Wang et al. 2003; see references within). In brief, the DIA module contains symmetric upper and lower guide blocks, four wedge-shaped thrust blocks, and six mounted tungsten carbide (WC) tipped anvils. A cubic specimen cavity is defined by six square $(4 \mathrm{~mm} \times 4 \mathrm{~mm})$, tipped fronts of WC anvils at the center of the module. The mechanical design of the DIA allows the cubic sample assembly to be compressed hydrostatically by applying force along the vertical axis across the guide blocks, in which the ram force is generated by gear linear actuators. Unlike traditional DIAs, the Deformation-DIA module (DDIA, Fig. 3) has two built-in hydraulic actuators (hereafter Z-axis pressure generators, i.e., P2 and P3 in Fig. 3), called differential rams, that are used to independently control the displacement of the upper and lower anvils. The capability of independent control for the differential rams allows the specimen to be deformed under controlled differential stress and strain. In this case, the modified DIA module can provide either a quasi-hydrostatic pressure environment (while the differential rams are inactive; in DIA mode) or a differential stress field (in D-DIA mode) on the sample.

A pressure-temperature controlling module was built to control the three sub-systems of the press; the linear actuators, two Z-axis pressure generators, and two transformers for temperature generation. Sample temperature was controlled via a cylindrical furnace of graphite, lanthanum chromite $\left(\mathrm{LaCrO}_{3}\right)$, or metal foil inserted in the sample assembly. Two AC power supplies were installed for different materials used at different pressure regimes; $12-\mathrm{V}$ (for low electrical resistant materials; i.e., graphite and metals) and 48-V (for high electrical resistant material, i.e., $\mathrm{LaCrO}_{3}$ ).

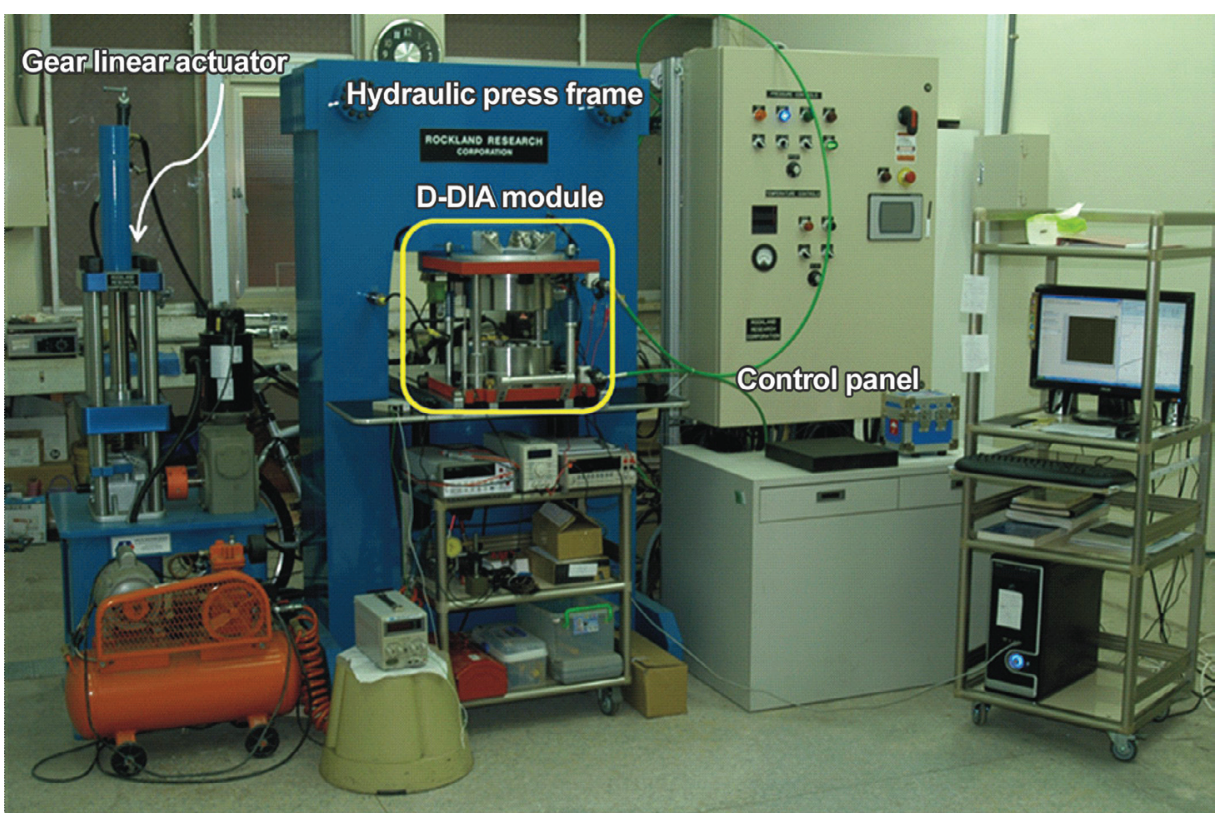

Fig. 1. High pressure apparatus system. The newly installed system includes a 1000-ton hydraulic press, a multi-anvil device (D-DIA module), and a pressure-temperature controlling system (control panel and computer system). The main ram force is provided by a gear linear actuator and the differential stress is driven by a pair of actuators (not shown in the photo). 


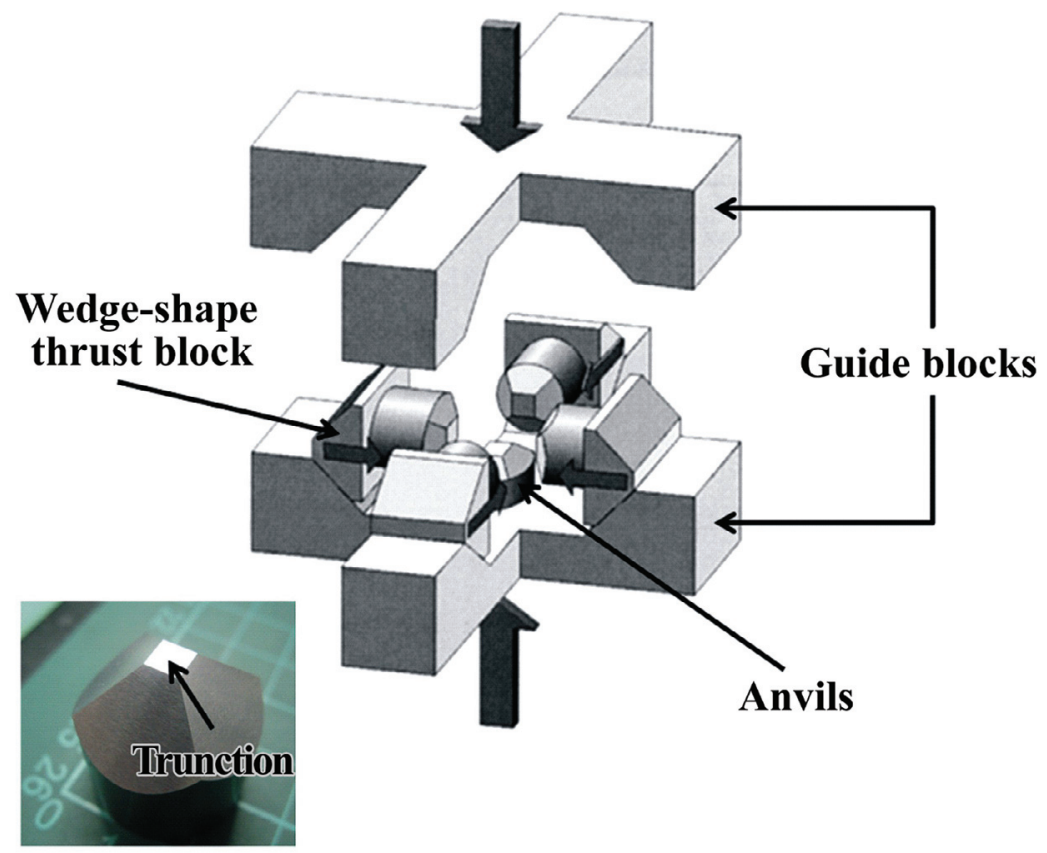

Fig. 2. Schematic diagram of the DIA cubic anvil module. Insert shows the WC anvil used in the DIA module with 4 mm truncation.

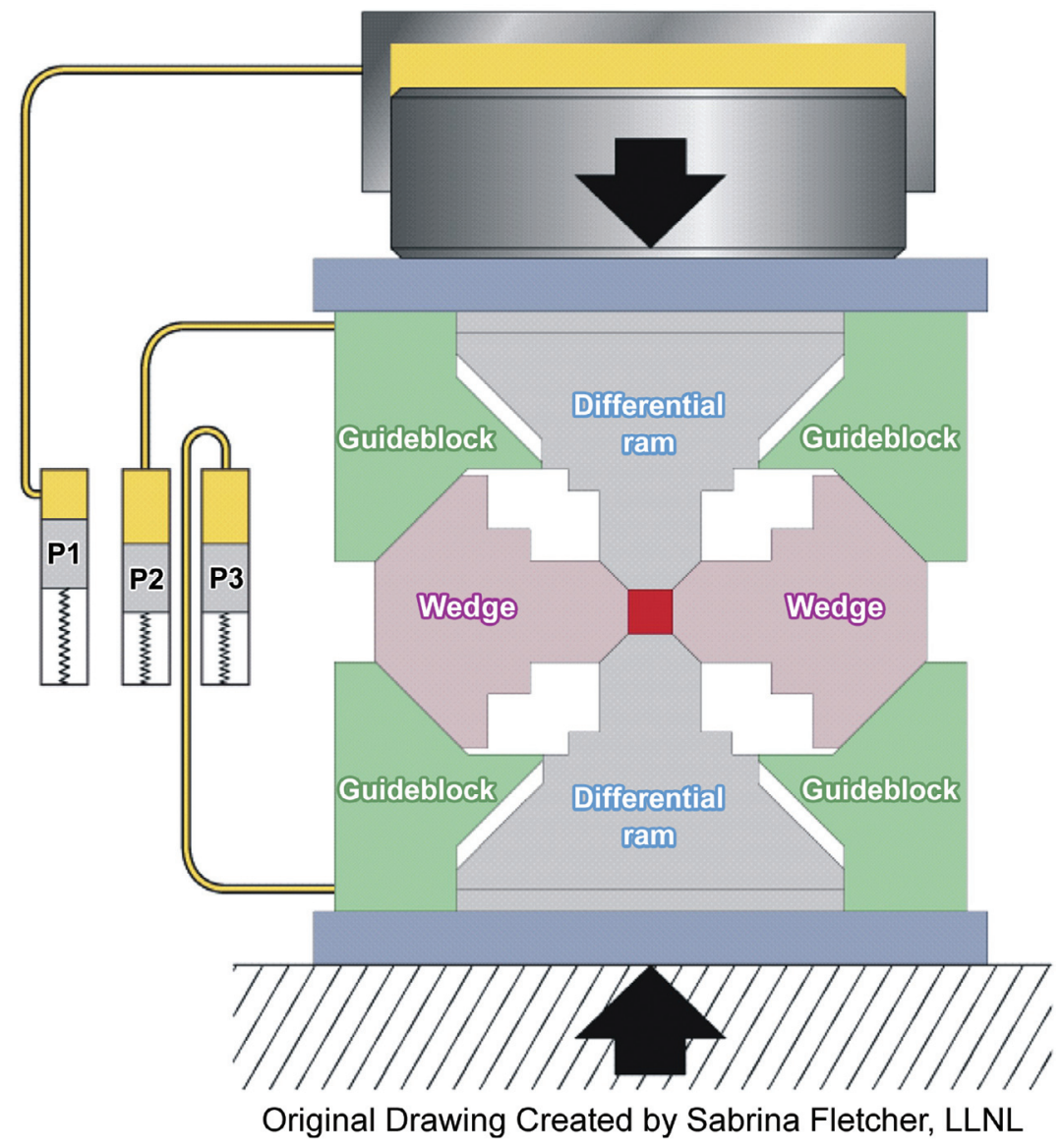

Fig. 3. Schematic diagram of a cross-section of the Deformation-DIA module. P1, P2, and P3 are the actuators. P1 (linear actuator shown in Fig. 1) provides the main ram force of the module, and $\mathrm{P} 2$ and $\mathrm{P} 3$ derive the differential ram forces to provide differential stress along the vertical axis of the specimen. 
LabVIEW software was used to create custom functions to control the mechanical hydraulic actuators for pressure control and the power supplies for temperature control. In this modified DIA module system, a vertical displacement transducer (LVDT - Linear Variable Differential Transformer) was introduced to monitor the distance between the top and bottom guide blocks during the course of experiments, i.e., to measure the deformation of the cell assembly. Therefore, the parameters of pressure, temperature, and LVDT from the controlling system could be recorded and simultaneously displayed on the computer monitor during the experiment.

\section{EXPERIMENTAL DESCRIPTION}

Pressure calibration (or pressure marking) is essential for performing experiments with the multi-anvil press without using synchrotron X-ray diffraction, especially for a newly installed high pressure apparatus. Here, the term "pressure" refers to amount of pressure placed on a "specimen" (or "cell"), not the applied ram force. Only a few factors are known to significantly affect the cell pressure: material and size of the pressure medium and cell assembly design. In this study, the cell pressure versus ram force relationship experiments were performed at room temperature using three different pressure mediums with several different cell geometries. The anvil truncation size for current pressure calibration was $4 \mathrm{~mm}$. The deformation behavior of the pressure medium was also investigated at high temperature for future high pressure thermal experiments.

The properties of pressure medium for high pressure and high temperature experiments require low thermal conductivity, low thermal expansion, and stability (meaning no phase transition and decomposition) under the elevated temperature and pressure conditions. Based on the above criteria, three different pressure mediums were tested in the study; boron-epoxy, mullite $\left(3 \mathrm{Al}_{2} \mathrm{O}_{3} \cdot 2 \mathrm{SiO}_{2}\right)$, and zirconia $\left(\mathrm{ZrO}_{2}\right)$, and their physical properties are shown in Table 1 . In order to produce a cell of the desired size, boron powder was mixed with an epoxy binder and then cold pressed into a mold. The boron-epoxy pressure medium was estimated to have a porosity of $~ 30 \%$ using the Archimedes' immersion technique. The mullite and zirconia were semi-sintered and also had a porosity of $30 \%$; the materials were purchased from the Department of Chemistry and Biochemistry, Arizona State University (COMPRES Multi-Anvil Cell Assembly Development Project).

The three pressure mediums were shaped into cubes with initial sizes of 6.1 and $6.5 \mathrm{~mm}$ edge length. A cylindrical cavity with a diameter of 2.4 or $3.2 \mathrm{~mm}$ was drilled in the center of each cube. For the pressure calibration at room temperature experiments, a simplified cell assembly without a heating furnace was used; the pressure calibrants (Bi and $\mathrm{ZnTe}$ ) were placed between the parts machined from the semi-sintered $\mathrm{MgO}$ and contacted with a pair of copper electrode leads connected to the surfaces of the top and bottom anvils (Fig. 4a).

Cell pressures were calibrated against the ram force at room temperature for different cell assemblies using the phase transitions in Bi (I-II and III-V transitions at 2.55 and $7.7 \mathrm{GPa}$, respectively, Lloyd 1971; Getting 1998) and ZnTe (12 GPa, Endo et al. 1982; Kusaba et al. 1993), where the electrical resistance changed dramatically across phase transitions within these materials. The change in electrical resistance across phase transitions in both materials was monitored using a two-wire electric resistance measurement

Table 1. Physical properties of pressure medium.

\begin{tabular}{lccc}
\hline & B-epoxy & Mullite & Zriconia \\
\hline Bulk-modulus $(\mathbf{G P a})$ & $185^{1}$ & $174^{3}$ & $204^{3}$ \\
Thermal conductivity $(\mathbf{W} / \mathbf{m} * \mathbf{K})$ & $27.4^{2}$ & $6.06^{3}$ & $2^{3}$ \\
Thermal expansion $\left(\times \mathbf{1 0}^{-6}{ }^{\circ} \mathbf{C}^{-1}\right)$ & $5^{2}$ & $5.4^{3}$ & $5.7^{3}$ \\
Porosity (\%) & 30 & 30 & 30.9 \\
\hline
\end{tabular}

Note: 1. Nelmes et al.(1993); 2. Shackelford and Alexander (2000); 3. Harper (2001).

(a)
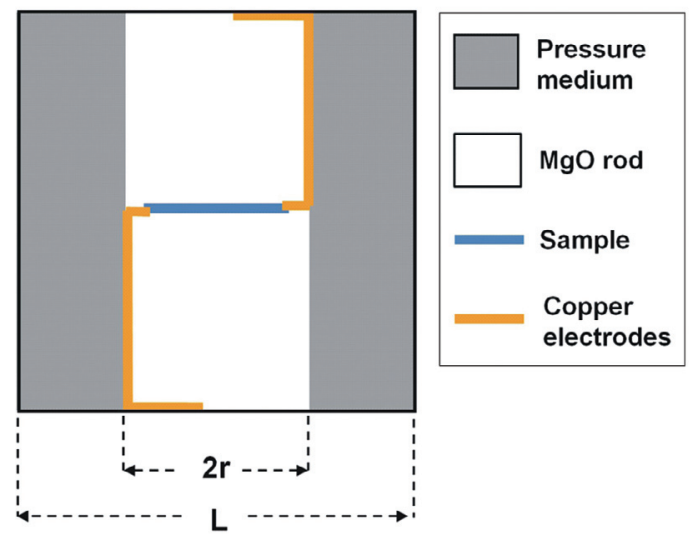

(b)

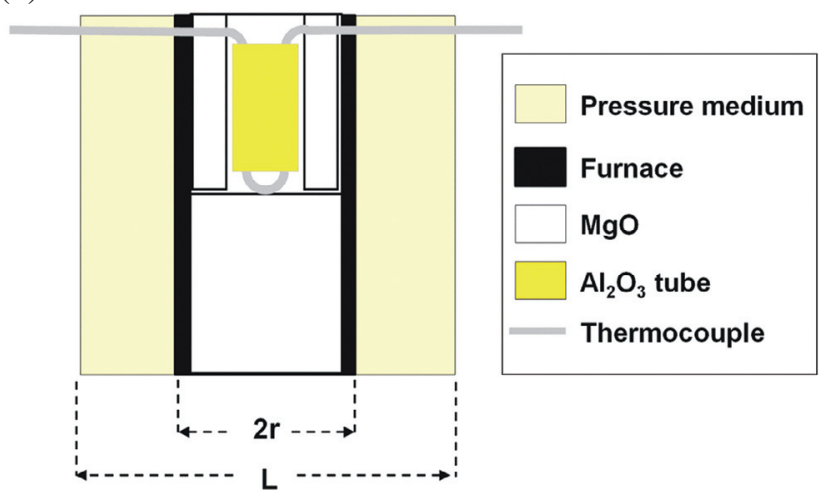

Fig. 4. Schematic diagrams of cell assemblies for room-temperature pressure calibration (a) and for high-temperature tests (b). " $2 \mathrm{r}$ " indicates the diameter of the cylindrical cavity, and " $L$ " is the edge length of the cell, as indicated in the text. 
method. The electric resistance against the applied ram force is shown in Fig. 5. The ram forces of the pressures for the phase transitions were defined as the mid-point of the curve in which the electric resistance decreased sharply within a very small interval of increasing ram force.

A simplified high temperature cell was designed to investigate the thermal behavior of the pressure medium materials at high temperature. For high temperature experiments, we typically used a 6.5 -mm cube with a cylindrical cavity (Fig. 4b). The temperature was generated by applying voltage to a straight cylindrical graphite furnace. A pair of Type $\mathrm{C}$ thermocouples (Re/W pair) was inserted from the top and its junction was located in the center of the cavity. The rest of the space within the sample chamber was filled using a $\mathrm{MgO}$ insert or plug. When the desired pressure was reached, we began to heat the sample. The temperature and deformation of the cell were monitored and recorded using the computer.

\section{RESULTS AND DISCUSSION}

The experiments were performed under a quasi-hydrostatic pressure environment without turning on the differential ram system (DIA mode). A total of 15 pressure calibration experiments were performed at room temperature with 3 different pressure mediums and various cell assembly designs; there were 14 runs using $\mathrm{Bi}$ as the pressure calibrant under an applied force of 100 tons and 1 run using $\mathrm{ZnTe}$ under an applied force of up to 150 tons. The results of the experiments are shown in Table 2. The high temperature experiments (three selected runs) were performed at $1000^{\circ} \mathrm{C}$ and $1200^{\circ} \mathrm{C}$, and their results are shown in Table 3 .

\subsection{Pressure Medium Materials}

Figure 6 shows the cell pressure calibrated against ram force among the three pressure mediums using the same cell assembly design $\left(6.5 \times 6.5 \times 6.5 \mathrm{~mm}^{3}\right.$ cube with 3.0 $\mathrm{mm}$ diameter cylindrical cavity; solid symbols with solid lines). The phase transitions of I-II (2.55 GPa) and IIII-V
(7.7 GPa) in Bi were observed at a mean ram force of 12.4 - 16.1 tons and 58.8 - 66.8 tons, respectively (Table 2). For $\mathrm{ZnTe}$, its semiconductor to metal transition of $12 \mathrm{GPa}$ was determined around at a ram force of 101.5 tons (Fig. 6 and Table 2). When comparing the ram force-induced phase transitions of $\mathrm{Bi}$ in a pressure medium, the pressure efficiency of boron-epoxy, zirconia, and mullite were similar to each other at a pressure of $\sim 2.55 \mathrm{GPa}$, but slightly different at $\sim 7.7 \mathrm{GPa}$; the performance of boron-epoxy and mullite were slightly better than zirconia. A possible explanation for this is that the bulk modulus of zirconia is slightly higher than those of boron-epoxy and mullite, $204 \mathrm{GPa}$ for zirconia compared with $\sim 180 \mathrm{GPa}$ for boron-epoxy and mullite (Table 1$)$ under the same porosity condition $(\sim 30 \%)$. Among the three pressure mediums, the differences in cell pressure calibrated against the ram force were small at both 2.55 and $7.7 \mathrm{GPa}$ for most of the calibration experiments, apart from the pressure of 7.7 GPa in the boron-epoxy cell showing nearly $10 \%$ variation $( \pm 5.6$ tons at a mean ram force of 60.0 tons). We speculated that the cause of the larger variation in calibration at a pressure of $7.7 \mathrm{GPa}$ in the boron-

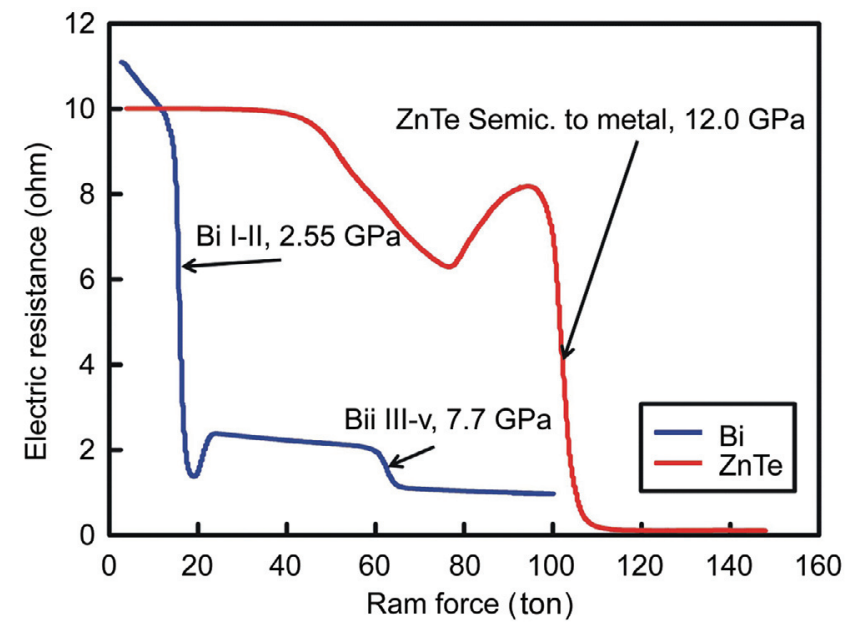

Fig. 5. Resistance measurements under applied ram force across the phase transitions of $\mathrm{Bi}$ and $\mathrm{ZnTe}$. The measurement of cell pressure is described in the text.

Table 2. Cell assembly designs before and after experiments, and transition pressures of pressure calibrants in different pressure medium.

\begin{tabular}{|c|c|c|c|c|c|c|c|}
\hline \multirow{2}{*}{$\begin{array}{l}\text { Pressure } \\
\text { medium }\end{array}$} & \multicolumn{2}{|c|}{ Cell size } & \multirow[b]{2}{*}{$D$ factor } & \multirow{2}{*}{$\begin{array}{c}\text { Bi I-II } \\
2.55 \text { GPa } \\
\text { (Tons) }\end{array}$} & \multirow{2}{*}{$\begin{array}{c}\text { Bi III-V } \\
7.7 \text { GPa } \\
\text { (Tons) }\end{array}$} & \multirow{2}{*}{$\begin{array}{c}\text { ZnTe } \\
12 \text { GPa } \\
\text { (Tons) }\end{array}$} & \multirow{2}{*}{$\begin{array}{c}\text { Final cube } \\
\text { length } \\
(\mathrm{mm})\end{array}$} \\
\hline & $\begin{array}{c}\text { Cube size } \\
(\mathbf{m m})\end{array}$ & $\begin{array}{c}\text { Cavity size } \\
\quad(\mathbf{m m})\end{array}$ & & & & & \\
\hline \multirow{2}{*}{ B-epoxy } & 6.5 & 3.0 & 3.05 & $16.1(12)$ & $60.0(56)$ & 101.5 & $5.00(5)$ \\
\hline & 6.5 & 3.2 & 2.87 & 16.7 & 67.6 & & $5.00(5)$ \\
\hline \multirow{2}{*}{ Zirconia } & 6.5 & 3.0 & 3.05 & $13.6(4)$ & $66.8(12)$ & & $4.90(5)$ \\
\hline & 6.5 & 2.4 & 3.83 & 11.3 & 40.9 & & $4.90(5)$ \\
\hline \multirow{2}{*}{ Mullite } & 6.5 & 3.0 & 3.05 & 12.4 & 58.8 & & $4.97(5)$ \\
\hline & 6.1 & 2.4 & 3.59 & 11.7 & 46.6 & & $4.60(5)$ \\
\hline
\end{tabular}


Table 3. Thermal behavior of pressure medium.

\begin{tabular}{|c|c|c|c|c|c|}
\hline \multirow[b]{2}{*}{$\begin{array}{l}\text { Pressure } \\
\text { medium }\end{array}$} & \multicolumn{2}{|c|}{ Cell size } & \multirow{2}{*}{$\begin{array}{l}\text { Max } \\
\text { load } \\
\text { (Tons) }\end{array}$} & \multirow{2}{*}{$\begin{array}{c}\text { Max } \\
\text { temperature } \\
\left({ }^{\circ} \mathrm{C}\right)\end{array}$} & \multirow{2}{*}{$\begin{array}{c}\text { Max } \\
\text { displacemen } \\
(\mu \mathrm{m})\end{array}$} \\
\hline & $\begin{array}{c}\text { Cube size } \\
\quad(\mathrm{mm})\end{array}$ & $\begin{array}{c}\text { Cavity size } \\
\quad(\mathbf{m m})\end{array}$ & & & \\
\hline B-epoxy & 6.5 & 3.0 & 51.1 & 1000 & -140 \\
\hline Zirconia & 6.5 & 2.8 & 33.5 & 1200 & 57 \\
\hline Mullite & 6.5 & 2.0 & 47.7 & 1000 & 18 \\
\hline
\end{tabular}

Note: The displacements shown in the table are the deformation of the cell that occurred after starting to heat the cell at peak pressure conditions. The displacement values represent the change of the size of the cell, either expanding (+) or contracting (-) during the heating.

epoxy cell was due to the inconsistent cold-press process in various batches prepared by different members of the laboratory. In the ZnTe calibration run with a maximum ram force of 150 tons, a blowout occurred at 73 tons during the decompression. After the press was opened, all six WC anvils were found to be shattered. A possible reason for the blowout may be due to the WC anvils not being strong enough to sustain the large applied load (i.e., 150 tons). This implies that the maximum pressure of DIA is limited by the strength of the WC anvils in the current module assembly. Nishiyama et al. (2008) developed a new assembly for a DIA-type high-pressure apparatus that allows the pressure to be generated above $12 \mathrm{GPa}$ without breaking the anvils at high tonnage ( $\sim 150$ tons). The specimen size for new assembly, however, is too small to meet our purposes for synthesis (see section 4.2 - Cell assembly design). Based on considerations of the life-time of WC anvils, no further high pressure calibrations were performed above $8 \mathrm{GPa}$ for zirconia and mullite using the DIA module.

\subsection{Cell Assembly Design}

We also evaluated the effect of cell design on pressure generation efficiency by varying the cube and cavity sizes (see Table 2); i.e., either a fixed cube size with a varying cavity size or a fixed cavity size with a varying cube size. The "D" factor was defined by the ratio of the diagonal length of the cube (square root of two times the cube length, $\sqrt{2} \mathrm{~L}$ ) to the diameter of the cavity hole (2r; see insert in Fig. 7) to describe the cell designs ( $D=\sqrt{2} \mathrm{~L} / 2 \mathrm{r}$ ). The " $\mathrm{D}$ " value for a typical cell size used in our laboratory was approximately 3.05 (blue circle, marked as "standard" with a relative pressure generation efficiency of " 1 " - see the definition below) for a cell of $6.5(\mathrm{~L}) \times 6.5(\mathrm{~L}) \times 6.5(\mathrm{~L}) \mathrm{mm}^{3}$ cube with a 3.0-mm diameter (2r) hole. A 3.0-mm diameter cavity designed for our cell assembly was used to optimize the use of the cell assembly with a 2-mm specimen synthesized/ hot-pressed at high pressure and temperature in future experiments. The cell assembly comprised a heating element (500- $\mu \mathrm{m}$ thick graphite tube) and a $\mathrm{MgO}$ tube, which served as insulation between sample and heating element. A sim-

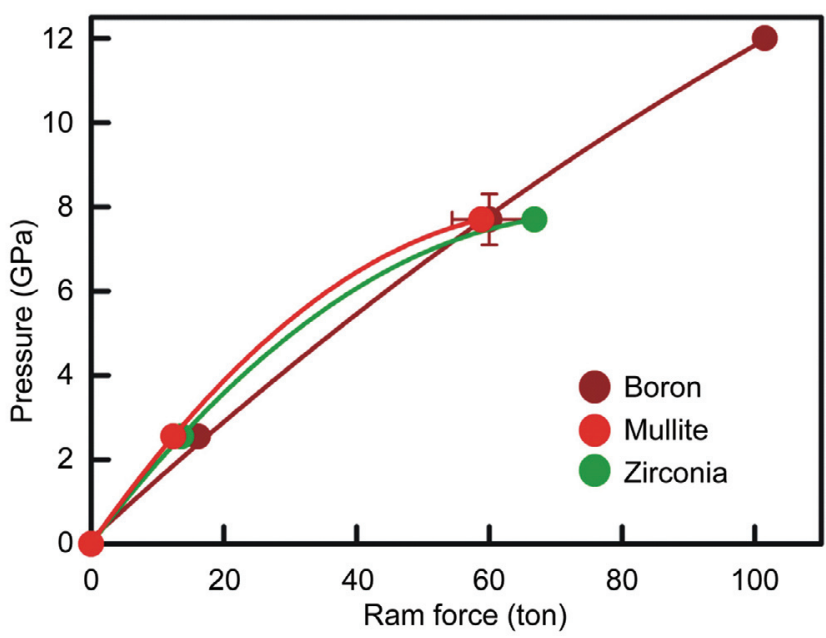

Fig. 6. Pressure calibration curves obtained at room temperature from three different pressure mediums; boron-epoxy (brown), mullite (red), and zirconia (green). The error bars indicate the variation in ram force for the cell pressure. For most of runs, the error bars are smaller than the size of the symbols.

ilarly designed cell is used for the high pressure research beamline X17B at the National Synchrotron Light Source of Brookhaven National Laboratory, USA (e.g., Li et al. 2001). The cell described above is referred to the "standard" cell in our laboratory. Different cell designs were also tested, see Table 2. As described in the 'Pressure medium materials' section, we found similar pressure generation efficiency among boron-epoxy, mullite, and zircon using the standard cell $(\mathrm{D}=3.05)$. In this section, the pressure generation efficiency of the cell was only distinguished by the geometry of the cell. The pressure efficiency was defined as $\left(\Delta \mathrm{F} / \mathrm{F}_{\mathrm{D}=3.05}\right)+1$, where $\Delta \mathrm{F}=\mathrm{F}_{\mathrm{D}=0.35}-\mathrm{F}_{\mathrm{D}}$, and $\mathrm{F}_{\mathrm{D}}$ is the ram force that induces a phase transition in the pressure calibrant with a given cell design. Figure 7 shows the general trend of increasing pressure generation efficiency with increasing " $\mathrm{D}$ " value. It is worth noting that the different designs only had minor effects on the efficiency (within 10\%) at low pressure (e.g., $2.55 \mathrm{GPa}$; Fig. 7, dashed line), but improved the efficiency remarkably $(20-40 \%)$ at high pressure (i.e., mullite and zircon at $7.7 \mathrm{GPa}$; Fig. 7, solid line). 


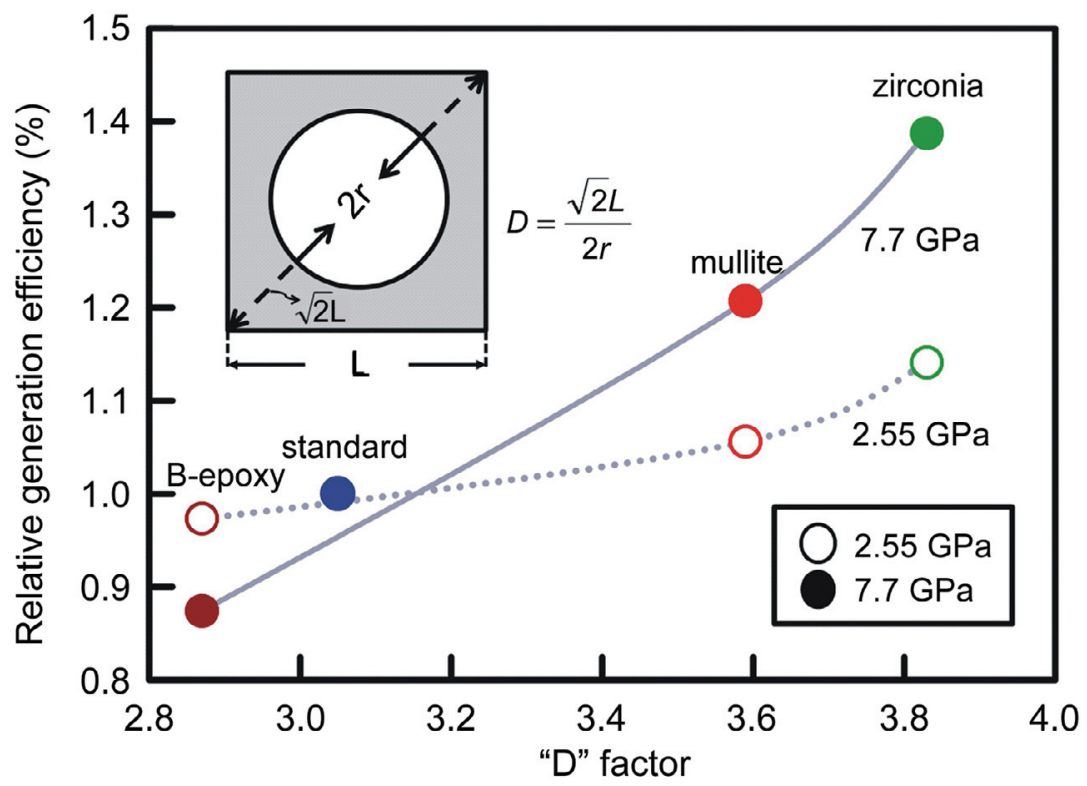

Fig. 7. Elation of sample-pressure efficiency and different cell design (defined by "D” factor). See text for a detailed description.

We also observed that the pressure generation efficiency at high pressures became less efficient compared to that at low pressures (brown symbols) when the " $\mathrm{D}$ " values were less than 3.05 .

\subsection{Thermal Behavior of Pressure Medium}

Performing high pressure experiments at high temperature to investigate the dynamics and properties of Earth materials is our ultimate goal. The pressure mediums of boron-epoxy, mullite, and zirconia were tested under high temperature conditions (Table 2). Figure 8 shows the deformation of boron-epoxy, zirconia, and mullite cells at high pressures and temperatures. Apparently, under similar pressure-temperature conditions (47.4 - 51.1 tons and $1000^{\circ} \mathrm{C}$ ), the size of the boron-epoxy cell (Fig. 8, brown line) started to decrease (negative displacement) while heating, but stopped decreasing when the temperature reached $1000^{\circ} \mathrm{C}$ (solid triangle). In contrast, the mullite cell (Fig. 8, red line) showed only a small increase in cube size (less than $20 \mu \mathrm{m}$ ) during the entire heating period. The experiment using zirconia pressure medium (Fig. 8, green line) was carried out at a lower pressure (29.5 tons), but higher temperature $\left(1200^{\circ} \mathrm{C}\right)$. The zirconia cell size continued to increase as temperature increased, even after the temperature reached a steady state at $1200^{\circ} \mathrm{C}$. A boron-epoxy pressure medium is often used in high pressure-high temperature in-situ X-ray experiments due to their transparency to $\mathrm{X}$-rays. In previous synchrotron studies, boron-epoxy cubes performing at high pressure and temperature conditions did not undergo severe deformation (Kung et al. 2002). The severe deformation of boron-epoxy cubes that occurred in our high-temperature experiments could be due to lower packing force during the cold compression, which led to lower packing density compared with those fabricated for use in the synchrotron experiments. At the moment, there are no demands for synchrotron studies in Taiwan, therefore, the boron-epoxy pressure medium is not the first choice for high temperature work. Compared to mullite, zirconia showed stronger thermal expansion at high temperature testing runs, which was due to the slightly higher thermal expansion coefficient of zirconia (Table 1). The current cell assembly design used in our experiments has the graphite resistant heater directly

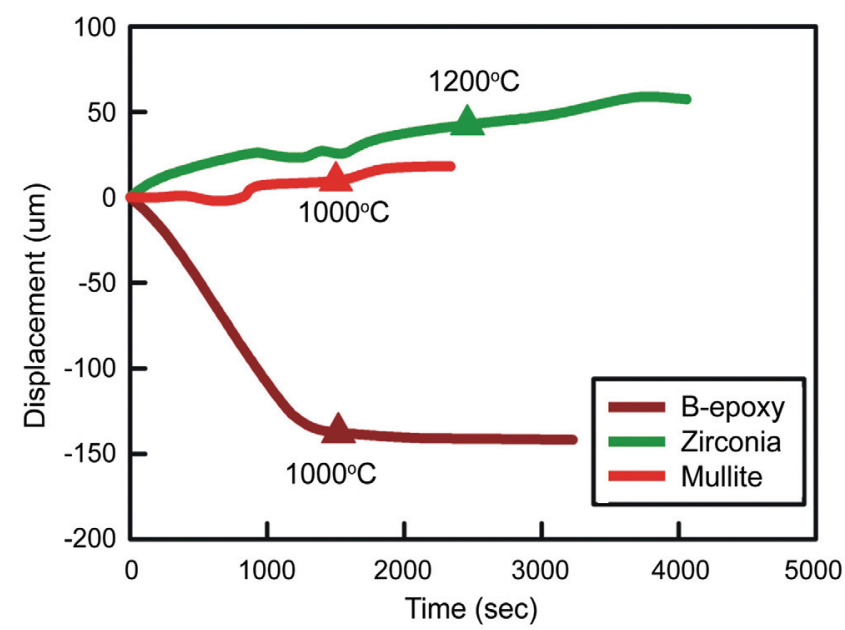

Fig. 8. Deformation of different pressure mediums at high temperature. The displacement " 0 " at time " 0 " represents the experimental condition at peak pressure, room temperature. The triangles represent the point at which the experimental temperature was reached (1000 or $\left.1200^{\circ} \mathrm{C}\right)$. 
contacting the pressure medium. A pressure medium with a low thermal conductivity will help to reduce the dissipation of heat generated from the heater that is transferred to the WC anvils. Based on the thermal properties of mullite and zirconia, we favor zirconia as the pressure medium for high temperature studies because of its low thermal conductivity (Table 1).

\section{SUMMARY}

A 1000-ton press frame with DIA-type module was installed in the Department of Earth Science, National Cheng Kung University. We have performed pressure calibration experiments at room temperature using three different materials; boron-epoxy, mullite, and zirconia, and used $\mathrm{Bi}$ and $\mathrm{ZnTe}$ as the pressure calibrants. To characterize the relationship between pressure efficiency and cell design, a " $\mathrm{D}$ " factor (the ratio of the diagonal length of the sample cube to the diameter of a cylindrical cavity) was used to describe the cell design geometry. The results show that all three materials had similar pressure generation efficiency under identical cell designs, the standard cell design in our laboratory has a "D" value of 3.05 (a $6.5 \times 6.5 \times 6.5 \mathrm{~mm}^{3}$ cube with a $3.0-\mathrm{mm}$ diameter cylindrical cavity). With different cell designs, we obtained the relationship between the pressure generation efficiency and the "D" value. Cells with larger " $D$ " values will have better pressure generation efficiency, especially at high pressure regimes. This relationship between cell design geometry and pressure generation efficiency was established in our laboratory for the first time and can be used a guideline for cell design in DIA type presses.

To carry out high pressure experiments under high temperature conditions, the thermal behavior of boronepoxy, mullite, and zirconia were investigated at high temperatures. We found that mullite and zirconia may function as better pressure medium at high temperature conditions than boron-epoxy. Based on the thermal properties, zirconia is the favored material to serve as a pressure medium due to its lower thermal conductivity, allowing it to also serve as a thermal insulator.

The pressure calibration at high temperatures is under way and will be reported in the near future. At the moment, we are able to synthesize the high pressure phases, like coesite $\left(1000^{\circ} \mathrm{C},>3 \mathrm{GPa}\right)$ and perovskite structure $\mathrm{CaGeO}_{3}$ $\left(1000^{\circ} \mathrm{C},>6.3 \mathrm{GPa}\right)$. After detailed pressure calibration performed at high temperature, this type of large volume press can be used to synthesize high pressure phases (Earth mantle phases) and study the chemical and physical properties of geomaterials at high pressures and temperatures, i.e., elements partitioning, phase equilibrium, in-situ measurements of elasticity, and transport properties, etc. This enables the geosciences community in Taiwan to extend their research focus to deeper Earth.
Acknowledgements We thank Kurt Leinenweber for discussion of the cell assembly development (COMPRES Multi-Anvil Cell Assembly Development Project). This research was supported by the grants of National Cheng Kung University and National Science Council (NSC) to JK (NSC95-2116-M-006-008 and NSC 96-2628-M-006-003).

\section{REFERENCES}

Akaogi, M. and S. Akimoto, 1977: Pyroxene-garnet solid-solution equilibria in the systems $\mathrm{Mg}_{4} \mathrm{Si}_{4} \mathrm{O}_{12}$ $\mathrm{Mg}_{3} \mathrm{Al}_{2} \mathrm{Si}_{3} \mathrm{O}_{12}$ and $\mathrm{Fe}_{4} \mathrm{Si}_{4} \mathrm{O}_{12}-\mathrm{Fe}_{3} \mathrm{Al}_{2} \mathrm{Si}_{3} \mathrm{O}_{12}$ at high-pressures and temperatures. Phys. Earth Planet. Inter., 15, 90-106, doi: 10.1016/0031-9201(77)90013-9. [Link]

Akaogi, M. and S. Akimoto, 1979: High-pressure phaseequilibria in a garnet lherzolite, with special reference to $\mathrm{Mg}^{2+}-\mathrm{Fe}^{2+}$ partitioning among constituent minerals. Phys. Earth Planet. Inter., 19, 31-51, doi: 10.1016/00 31-9201(79)90088-8. [Link]

Bundy, F. P., H. T. Hall, H. M. Strong, and R. H. Wentorf, 1955: Man-made diamonds. Nature, 176, 51-55, doi: 10.1038/176051a0. [Link]

Chen, G., B. Li, and R. C. Liebermann, 1996: Selected elastic moduli of single-crystal olivines from ultrasonic experiments to mantle pressures. Science, 272, 979-980, doi: 10.1126/science.272.5264.979. [Link]

Coes, L., 1953: A new dense crystalline silica. Science, 118, 131-132, doi: 10.1126/science.118.3057.131. [Link]

Dobson, D. P., A. P. Jones, R. Rabe, T. Sekine, K. Kurita, T. Taniguchi, T. Kondo, T. Kato, O. Shimomura, and S. Urakawa, 1996: In-situ measurement of viscosity and density of carbonate melts at high pressure. Earth Planet.Sci.Lett., 143, 207-215, doi: 10.1016/0012-821 X(96)00139-2. [Link]

Endo, S., A. Yoneda, M. Ichikawa, S. Tanaka, and S. Kawabe, 1982: High pressure study of transition in ZnTe by manganin coil method. J. Phys. Soc. Jpn., 51, 138-140, doi: 10.1143/JPSJ.51.138. [Link]

Frost, D. J., B. T. Poe, R. G. Trønnes, C. Liebske, A. Duba, and D. C. Rubie, 2004: A new large-volume multianvil system. Phys. Earth Planet. Inter., 143-144, 507-514, doi: 10.1016/j.pepi.2004.03.003. [Link]

Getting, I. C., 1998: New determination of the bismuth I-II equilibrium pressure: A proposed modification to the practical pressure scale. Metrologia, 35, 119-132, doi: 10.1088/0026-1394/35/2/7. [Link]

Harper, C., 2001: Handbook of Ceramics Glasses, and Diamonds. McGraw-Hill Professional, 1 edition, 848 pp.

Inoue, K. and T. Asada, 1973: Cubic anvil x-ray diffraction press up to $100 \mathrm{kbar}$ and $1000^{\circ} \mathrm{C}$. Jpn. J. Appl. Phys., 12, 1786-1793, doi: 10.1143/JJAP.12.1786. [Link]

Ito, E. and D. J. Weidner, 1986: Crystal growth of $\mathrm{MgSiO}_{3}$ perovskite. Geophys. Res. Lett., 13, 464-466, doi: 10. 
1029/GL013i005p00464. [Link]

Ito, E., E. Takahashi, and Y. Matsui, 1984: The mineralogy and chemistry of the lower mantle: An implication of the ultrahigh-pressure phase relations in the system $\mathrm{MgO}-\mathrm{FeO}-\mathrm{SiO}_{2}$. Earth Planet. Sci. Lett., 67, 238-248, doi: 10.1016/0012-821X(84)90119-5. [Link]

Kung, J., B. Li, D. J. Weidner, J. Zhang and R. C. Liebermann, 2002: Elasticity of $\left(\mathrm{Mg}_{0.83}, \mathrm{Fe}_{0.17}\right) \mathrm{O}$ Ferropericlase at high pressure: Ultrasonic measurements in conjunction with X-radiation techniques. Earth Planet. Sci.Lett., 203, 557-566, doi: 10.1016/S0012-821X(02) 00838-5. [Link]

Kunimoto, T. and T. Irifune, 2010: Pressure generation to $125 \mathrm{GPa}$ using a 6-8-2 type multianvil apparatus with nano-polycrystalline diamond anvils. J. Phys.: Conf. Ser., 215, 1-7, doi: 10.1088/1742-6596/215/1/012190. [Link]

Kusaba, K., L. Galoisy, Y. Wang, M. T. Vaughan, and D. J. Weidner, 1993: Determination of phase transition pressures of ZnTe under quasihydrostatic conditions. Pure Appl. Geophys., 141, 643-652, doi: 10.1007/BF00998 350. [Link]

Li, B., R. C. Liebermann, and D. J. Weidner, 2001: $P-V-V_{p^{-}}$ $V_{s}-T$ measurements on wadsleyite to $7 \mathrm{GPa}$ and $873 \mathrm{~K}$ : Implications for the $410-\mathrm{km}$ seismic discontinuity. $J$. Geophys. Res., 106, 30579-30591, doi: 10.1029/2001 JB000317. [Link]

Lloyd, E. C., 1971: Accurate characterization of the highpressure environment, US National Bureau of Standards, Washington DC, 1-3 pp.

Nelmes, R. J., J. S. Loveday, D. R. Allan, J. M. Besson, G. Hamel, P. Grima, and S. Hull, 1993: Neutron- and $\mathrm{X}$-ray-diffraction measurements of the bulk modulus of boron. Phys. Rev. B, 47, 7668-7673, doi: 10.1103/ PhysRevB.47.7668. [Link]
Nishiyama, N., Y. Wang, T. Sanehira, T. Irifune, and M. L. Rivers, 2008: Development of the Multi-anvil Assembly 6-6 for DIA and D-DIA type high-pressure apparatuses. High Pressure Res., 28, 307-314, doi: 10.10 80/08957950802250607. [Link]

Ringwood, A. E., 1958: Olivine-spinel transition in fayalite. Geol. Soc. Am. Bull., 69, 129-129, doi: 10.1130/00167606(1958)69[129:OTIF]2.0.CO;2. [Link]

Ringwood, A. E., 1963: Olivine - Spinel transformation in cobalt orthosilicate. Nature, 198, 79-80, doi: 10.1038/ 198079a0. [Link]

Ringwood, A. E. and M. Seabrook, 1962: Olivine-spinel equilibria at high pressure in the system $\mathrm{Ni}_{2} \mathrm{GeO}_{4}-\mathrm{Mg}_{2}-$ $\mathrm{SiO}_{4}$. J. Geophys. Res. 67, 1975-1985, doi: 10.1029/JZ 067i005p01975. [Link]

Rubie, D. C., 1999: Characterising the sample environment in multianvil high-pressure experiments. Phase Transit., 68, 431-451, doi: 10.1080/01411599908224526. [Link]

Shackelford, J. F. and W. Alexander, 2000: CRC Materials Science and Engineering Handbook. CRC Press, Third Edition, 1980 pp.

Wang, Y., W. B. Durham, I. C. Getting, and D. J. Weidner, 2003: The deformation-DIA: A new apparatus for high temperature triaxial deformation to pressures up to 15 GPa. Rev. Sci. Instrum., 74, 3002-3011, doi: 10.1063/ 1.1570948. [Link]

Xu, Y., T. J. Shankland, and B. T. Poe, 2000: Laboratorybased electrical conductivity in the Earth's mantle. $J$. Geophys. Res., 105, 27865-27875, doi: 10.1029/2000 JB900299. [Link]

Yagi, T. and S. I. Akimoto, 1976: Direct determination of coesite-stishovite transition by in-situ X-ray measurements. Tectonophysics, 35, 259-270. doi: 10.1016/00 40-1951(76)90042-1. [Link] 